\title{
Active delivery of the anterior arm and incidence of second-degree perineal tears: a clinical practice evaluation
}

\author{
Nicolas Mottet ${ }^{*}$, Marine Bonneaud, Astrid Eckman-Lacroix, Rajeev Ramanah and Didier Riethmuller
}

\begin{abstract}
Background: Evaluate the feasibility of active delivery of the anterior arm during spontaneous delivery. This maneuver could decrease incidence of second-degree perineal tears because it reduces fetal biacromial diameter.

Methods: An observational comparative prospective study was conducted at our teaching maternity from July 2012 to March 2013. The study included 199 nulliparous women $\geq 18$ years, who met the following criteria: singleton pregnancy, vaginal delivery with occiput anterior presentation, on epidural analgesia, from 37 weeks of gestation onward. The distribution of rate and type of perineal tears were compared between two groups: a non-exposed group and a group exposed to the maneuver.

Results: A total of 101 patients were exposed to Couder's maneuver (CM) and 98 patients were not exposed. In the intervention group, 3 failures of the maneuver were reported. The maneuver was considered easy in $80 \%$ of cases, moderately easy in $12 \%$ and difficult in $8 \%$ of cases. There was a significant difference $(p=0.03)$ in the distribution of perineal tears between the two groups. There was a significant reduction $(p<0.001)$ in the number of second-degree perineal tears in the patients exposed to CM. There was no significant difference in the rate of anterior perineal trauma between the exposed and non-exposed arms.
\end{abstract}

Conclusions: CM in primiparous women at term is feasible with a low failure rate and influences the distribution of perineal tears by lowering second-degree perineal tears in a highly significant manner $(p<0.01)$.

Keywords: Levator ani muscle injury, Perineal laceration, Vaginal delivery

\section{Background}

The last few years, much attention has been focused on obstetric anal sphincter injuries prevention and the indications for episiotomy. However, levator-ani muscle injuries form an important component of pelvis floor trauma and occur in 13 to $36 \%$ of women who deliver vaginally [1-5]. These lesions increase the risk of cystocele and uterine prolapse according to a literature review by Schwertner et al. [6].

Promoting obstetric maneuvers that improve visual and manual perineal management appears to be necessary to prevent perineal trauma during fetal head and shoulders delivery. Initially in Ritgen's maneuver, the

\footnotetext{
* Correspondence: ncmottet@gmail.com

Department of Obstetrics and Gynecology- Besancon University Medical
Center, CHRU Jean Minjoz, Alexander Fleming Boulevard, 25000 Besancon,

Department of Obstetrics and Gynecology- Besancon University Medical
Center, CHRU Jean Minjoz, Alexander Fleming Boulevard, 25000 Besancon, France
}

(c) The Author(s). 2017 Open Access This article is distributed under the terms of the Creative Commons Attribution 4.0 International License (http://creativecommons.org/licenses/by/4.0/, which permits unrestricted use, distribution, and reproduction in any medium, provided you give appropriate credit to the original author(s) and the source, provide a link to the Creative Commons license, and indicate if changes were made. The Creative Commons Public Domain Dedication waiver (http://creativecommons.org/publicdomain/zero/1.0/) applies to the data made available in this article, unless otherwise stated.

fetal chin is pulled interiorly to keep flexion of the fetal head and control speed of delivery between contractions. But actually, some practices of this maneuver deviate from its initial description. Authors describe a modified Ritgen's maneuver during contractions [7] and others use this maneuver by hooking the chin increasing the diameter oh the head on the perineum [8] . What actually does show the most significant reduction in severe perineal tears is the Finnish method and a complete teaching package [9-12]. But no systematic reviews have been published comparing different perineal support during the second stage of labour for reducing perineal trauma [13].

Delivery of the infant's shoulders is usually assisted by downward traction first to free the anterior shoulder. Then, the posterior shoulder is delivered with a risk of perineal tears because of tension on the perineum 
already weakened by fetal head delivery. Management of shoulders during delivery is a research area to improve perineal care. Active delivery of the anterior arm with Couder maneuver $(\mathrm{CM})$ can be benefit because it has the advantage of reducing fetal biacromial diameter. This maneuver is specially described to manage shoulder dystocia especially when the posterior shoulder is in the pelvis and the anterior shoulder is wedged against the pubis [14] . In our center, CM is usually performed during normal deliveries, but its impact on perineal tears has never been described.

The objective of this study was to evaluate the feasibility of $\mathrm{CM}$ and its impact on second-degree perineal tears. There has so far been no report in the literature on the usefulness of this maneuver.

\section{Methods}

\section{Study Design}

We carried out a prospective comparative non-randomized study in our teaching high-risk maternity from July 2012 to March 2013. The study respected ethical rules set by our local ethical committee (Institutional Review Board of Besancon University Medical Center "Comité Protection des Personnes CPP EST II EST-II"). The study took place at the department of Obstetric at Besancon University Medical Center, with an obstetric unit with 2,800 yearly deliveries. The study adhered to STROBE guidelines. Women likely to be included in the study were informed of the study and modalities of $\mathrm{CM}$ during the last medical visit with a recall at admission in the delivery room. An information sheet explaining the aim and usefulness of the study was given to them. All volunteers gave written informed consent.

A group of consecutive women exposed to CM according to our clinical practice was compared to a control group with spontaneous delivery of the shoulder. Women were enrolled if they agreed to participate and were divided into two groups based on their choice to receive or not the maneuver. A control group of consecutive women with a spontaneous delivery was collected. The two groups were compared for age, weight gain, BMI, maternal comorbidities and new borns characteristics (Weight, bi-acromial diameter, Apgar score).

\section{Participants}

The population of this study was women with a spontaneous vaginal delivery after 37 weeks of gestation.

Women were included if they were aged between 18 and 45 years old, with a singleton pregnancy, midpelvic cephalic presentation at the beginning of expulsive efforts and spontaneous occiput anterior delivery.

Women who refused to participate or were deprived of liberty by judicial or administrative decision or under legal protection were not included.

\section{Data collection}

An electronic case report form was used to collect demographic and clinical data on the woman and the new born. Maternal and neonatal serious events were collected.

\section{Intervention}

In our center, $\mathrm{CM}$ is usually performed during normal deliveries. In $\mathrm{CM}$, the anterior fetal arm is manually brought down as the shoulders are being delivered. The maneuver, which was initially described for treating shoulder dystocia, has the advantage of reducing fetal biacromial diameter. When there is insufficient room to deliver the anterior shoulder with the posterior shoulder in the pelvis, the anterior arm can be delivered, which brings the anterior shoulder under the pubis [15]. The birth attendant inserts the index and middle fingers of the hand opposite the fetal face under the mother's pubic symphysis along the fetal humerus (Fig. 1). The fetal head is slightly tilted downward with the free hand (Fig. 2). The two fingers are placed on the humerus like a splint and the arm is pushed toward the fetal back (Fig. 3). The fetal hand then appears under the maternal pubic symphysis, allowing the anterior arm to be delivered (Fig. 4). The diameter pushing down on the posterior perineum is thus reduced from $13 \mathrm{~cm}$ (biacromial diameter) to less than $10 \mathrm{~cm}$ (axillo-acromial diameter) (Fig. 5). Midwives and obstetrician in our maternity are

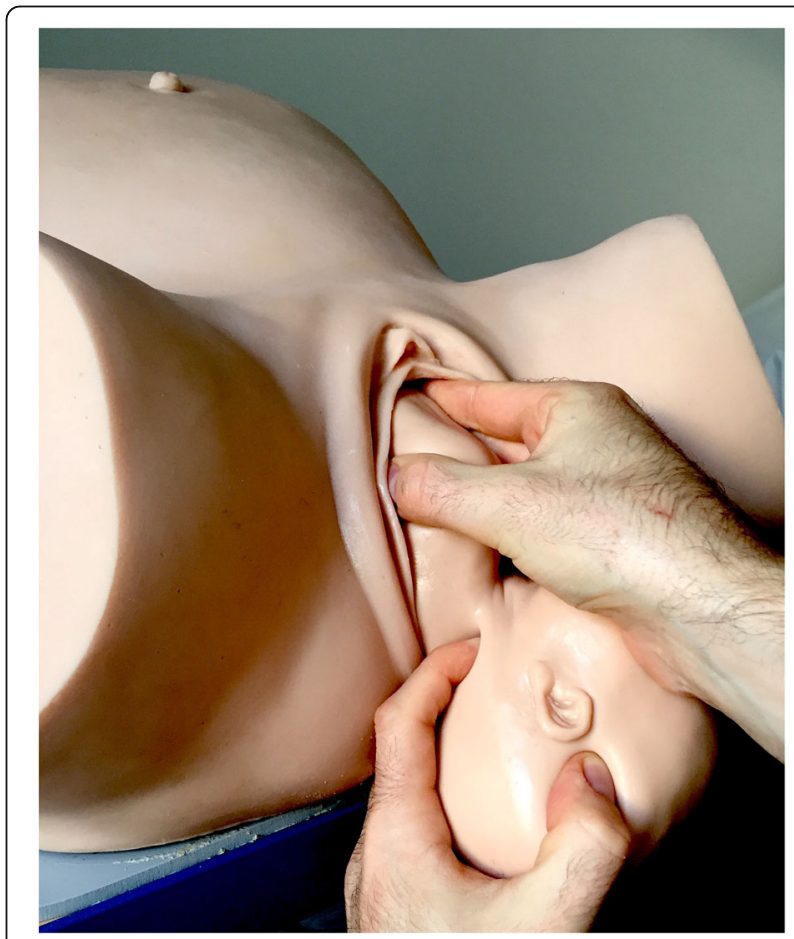

Fig. 1 Index and middle fingers insertion with the hand opposite the fetal face [NM] 


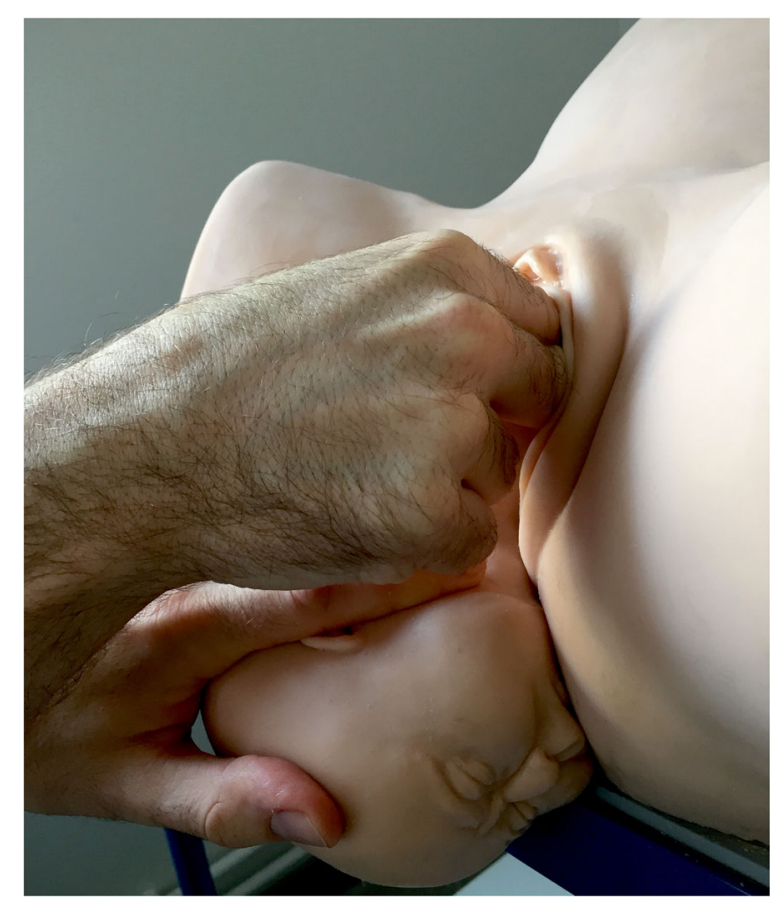

Fig. 2 Fetal head slightly tilted downward with the free hand [NM]

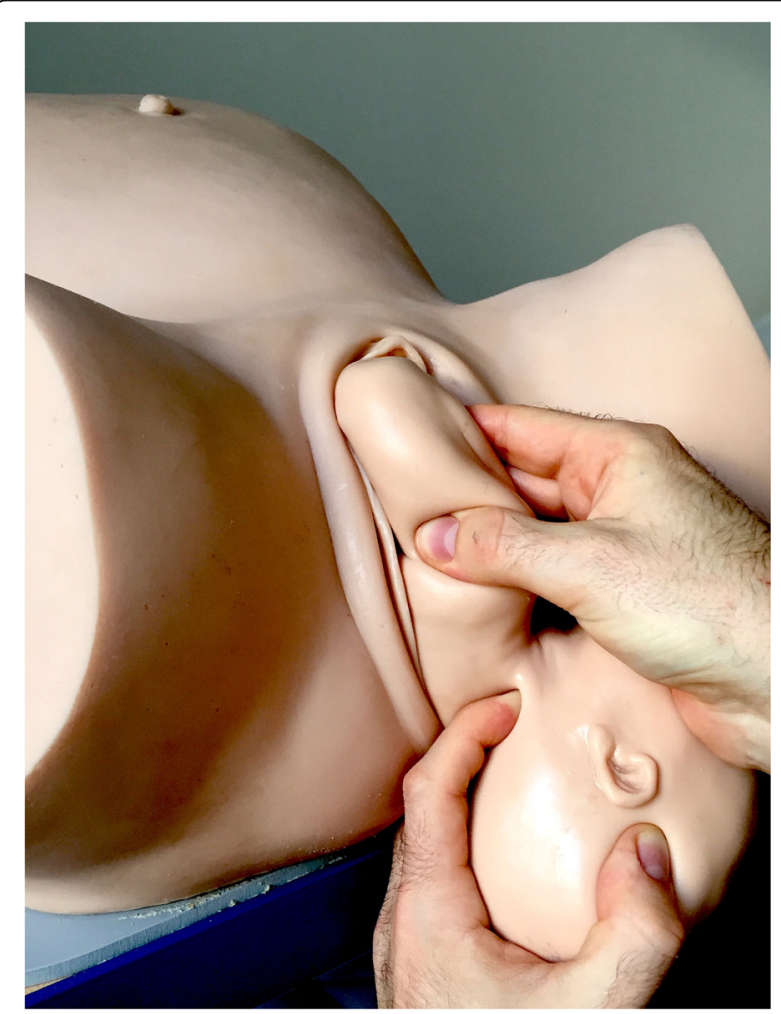

Fig. 3 Two fingers are placed on the humerus like a splint [NM]

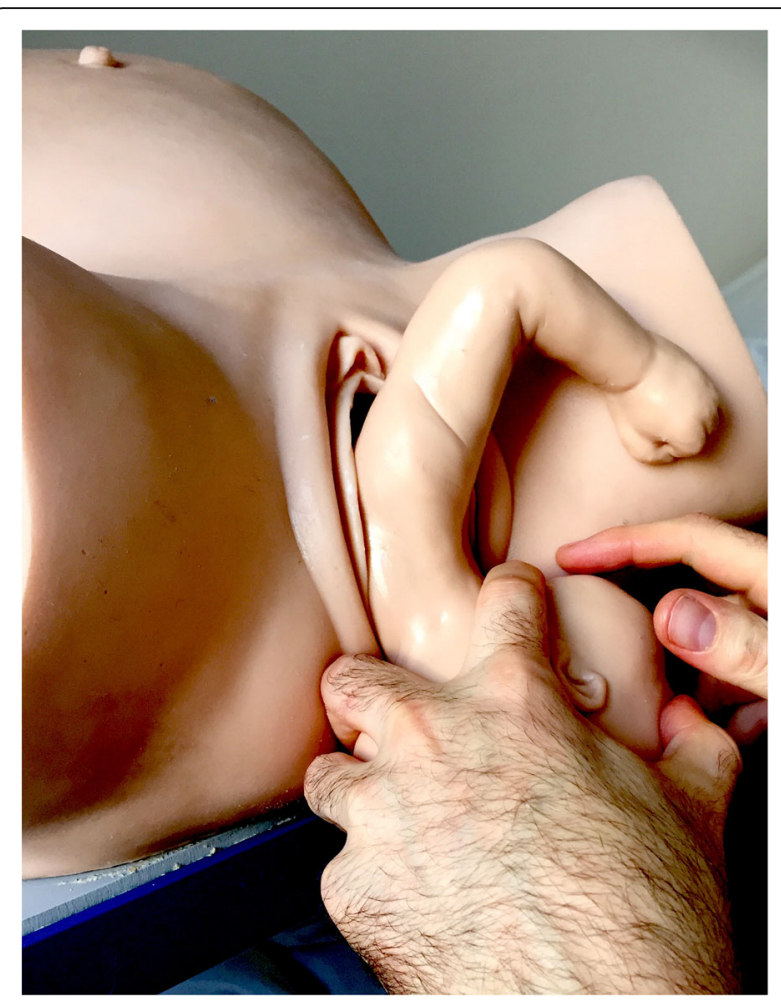

Fig. 4 Fetal hand appears under the maternal pubic symphysis, allowing the anterior arm to be delivered [NM]

accustomed to practice this maneuver at delivery to protect perineum.

In this study, midwives performed $\mathrm{CM}$ and were asked to judge the difficulty of the maneuver: easy, moderately easy or difficult. They were trained to safely practice this technique. Two training sessions took place before the study. One recapped the principle behind the maneuver and the other involved training on a birthing simulator

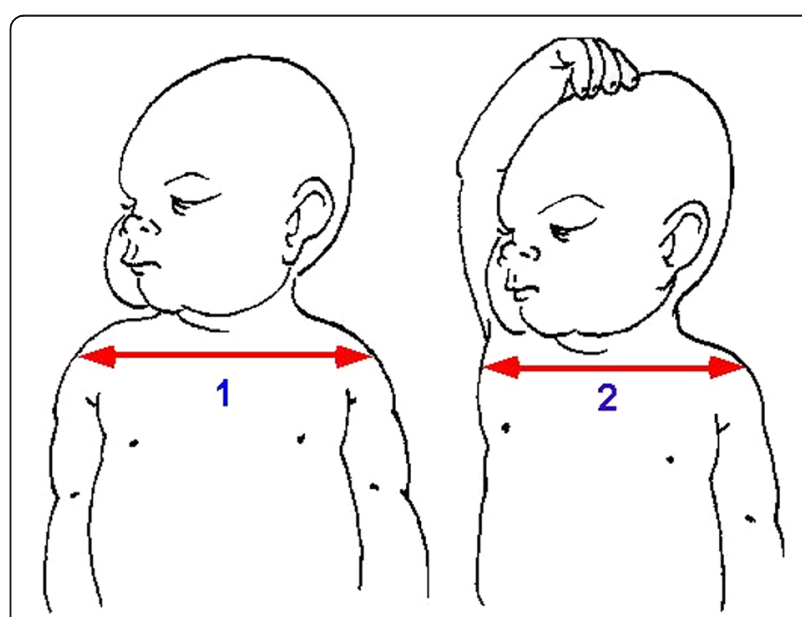

Fig. 5 Reduction of bisacromial diameter into acromio-thoracic diameter, leading to a $30 \mathrm{~mm}$ decrease [NM] 
(MODEL-med "Sophie and her Mum Full Birth Obstetric Trainer"). All midwives were also trained in the evaluation and classification of perineal tears.

\section{Outcomes}

The primary outcome was the success rate of the maneuver. Secondary outcomes were types of perineal tears according to the Royal College of Obstetricians and Gynaecologists' classification [16], and neonatal birth trauma (fracture of the clavicle and humerus). Absence of fracture was checked by a pediatric examination during the maternity stay.

\section{Statistical analysis}

To ensure that this study was statistically reliable, we estimated how many subjects were needed using the tool BioStat ${ }^{\circ}$. Prospective studies have shown that second degree occur in $13-36 \%$ of women who deliver vaginally $[5,17-22]$. Based on our usual rates of perineal trauma in nulliparous women, we hypothesized that the frequency of second-degree tears would be $28 \%$ in the nonexposed group and $10 \%$ in the exposed group [23]. No studies in the literature are available on the rate of perineal tears after CM. Allowing for an alpha risk of 5\% and a power of $90 \%$, the number of subjects that was required in each group was at least 98. In some cases of emergency, some women would be included too early without respect of inclusion criteria (incorrect diagnosis of fetal head station or presentation for example). These situations were not protocol deviation but inclusion errors independent of the treatment or its outcome. Thus, the intention to treat analysis was performed for all "well randomised" women after exclusion of wrongly included women (Fig. 6).

Descriptive statistics were calculated, including frequencies and means. Continuous data were compared using a $t$-test if the variable was normally distributed or Mann Whitney test for non-parametric variables. The Chi-square test (Fisher's exact test if necessary) was used for categorical variables. Statistical significance was considered at $p$-value $\leq 0.05$. Data were analyzed with SAS 9.3 for Windows (SAS Institute Inc., Cary, NC, USA).

\section{Results}

A total of 107 consecutives women exposed to CM were included and compared with 108 included in the control group. Sixteen women who in the end did not meet the inclusion criteria were excluded ( 9 assisted births before the beginning of expulsive efforts, 5 occiput-posterior delivery 2 cesareans during labor,). In these 9 cases of assisted delivery, a vacuum was used for non-reassuring fetal status before the beginning of expulsive efforts. Finally, two groups were compared: 101 consecutive women in the intervention group compared to 98 consecutive control women. The final number of patients was therefore 199 .

As presented in the Table 1, clinical and obstetrical characteristics were not different between the two groups. The average bi-acromial diameter and birth weight of the children in each group were similar and

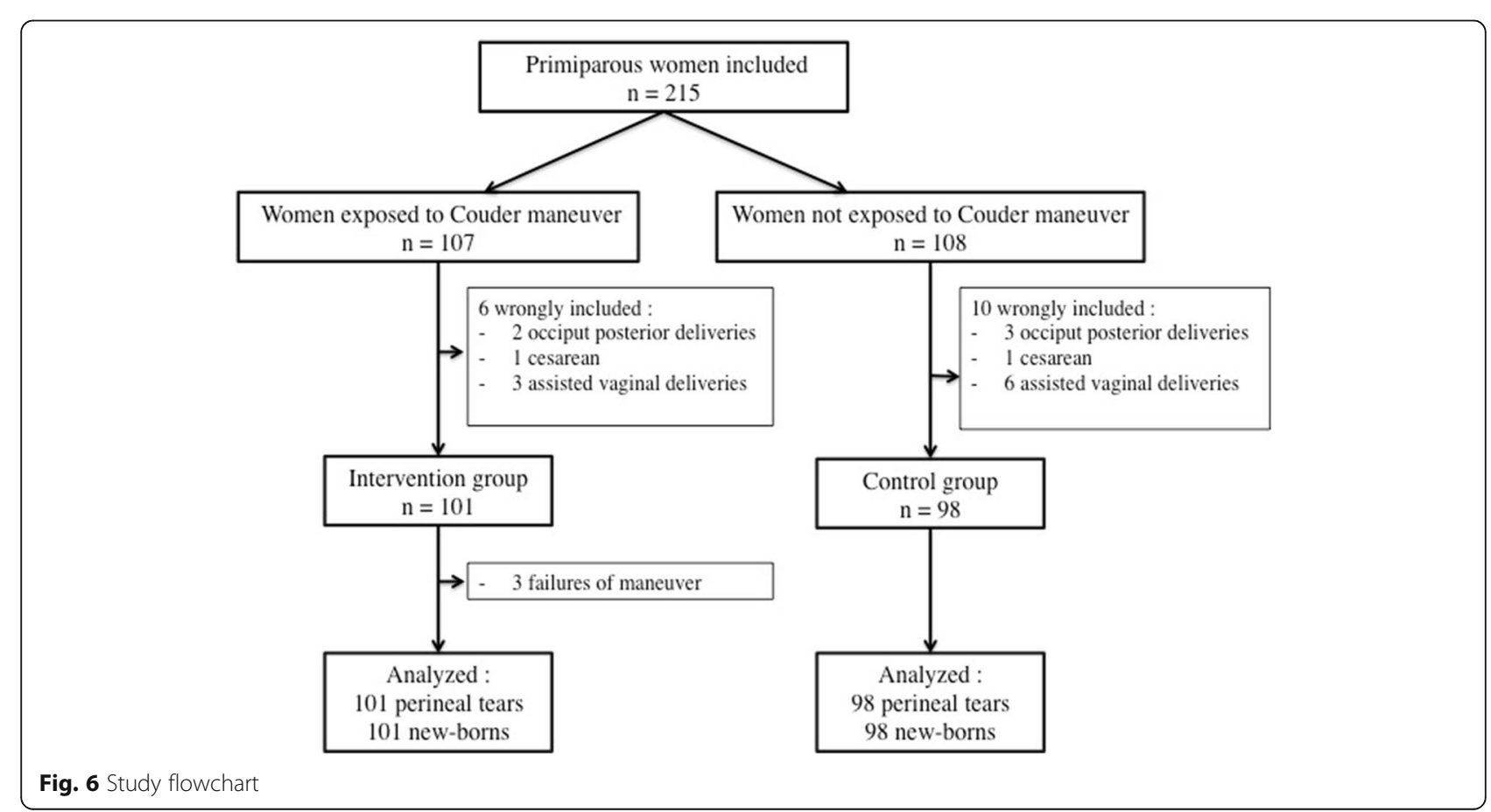


Table 1 Maternal and new-borns characteristics

\begin{tabular}{lll}
\hline & $\begin{array}{l}\text { Couder group } \\
(n=101)\end{array}$ & $\begin{array}{l}\text { Control group } \\
(n=98)\end{array}$ \\
\hline Maternal characteristics: & 26.9 & 27.8 \\
Maternal age (years) & 21.5 & 22.1 \\
BMl $\left(\mathrm{kg} / \mathrm{m}^{2}\right)$ & 13.6 & 13.7 \\
Weight gain $(\mathrm{kg})$ & & \\
Comorbidities: & $7(6.9 \%)$ & $8(8.1 \%)$ \\
-Diabetes & $2(1.9 \%)$ & $1(1 \%)$ \\
-Hypertension & $10(9.9 \%)$ & $8(8.2 \%)$ \\
-Others & & \\
New borns characteristics: & $3228[2880-4350]$ & $3129[2340-3910]$ \\
Mean birth weight $(\mathrm{g})$ & $123+/-10$ & $121+/-9.5$ \\
Biacromial diameter $(\mathrm{mm})$ & $3(3 \%)$ & $2(2 \%)$ \\
Apgar score $<7$ (5 min) & &
\end{tabular}

BMI Body mass index

birth weight values ranged from $2340 \mathrm{~g}$ to $4350 \mathrm{~g}$. There was no difference in the distribution of birth weight and Apgar score in the two groups.

In the intervention group, 3 (3\%) failures of the maneuver were reported. The maneuver was considered easy in $80 \%$ of cases, moderately easy in $12 \%$ and difficult in $8 \%$ of cases. Any clavicle or humerus fracture was recorded after a pediatric examination.

There was a significant difference concerning the secondary criteria. We found a significant difference $(p=0.03)$ in the rate of perineal tears between the two groups. No episiotomy was performed in this study. We found a significant reduction in the number of second-degree perineal trauma in the patients exposed to CM $(p<0.01)$ and a significant increase in first-degree tears $(p=0.03)$ (Table 2). No third and no fourth degree perineal tears were found. The number of intact perineums was higher in the group exposed to CM, but there was no significant difference. All the second-degree perineal tears avoided by CM were thus uniformly distributed in first-degree perineal tears or intact perineum. When there was second-degree trauma of the anal triangle, there was no difference in birth weight between the two groups (3380 g vs. $3370 \mathrm{~g}$ ). We did not observe any significant difference $(p=0.33)$ in the rate of anterior perineal trauma between the exposed arm (43.6\%) and non-exposed arm (36.7\%) (Additional file 1).

\section{Discussion}

\section{Main findings}

Couder maneuver in primiparous women at term is feasible with a low failure rate and influences the distribution of perineal tears by lowering second-degree perineal tear in a highly significant manner $(p<0.01)$. In our series, there were three times less second-degree perineal lesions in the patients who were exposed to this maneuver. These avoided lesions became instead first-degree perineal trauma or intact perineum. Although our study did not show any significant differences in the rates of intact perineums between the two groups, our exposed group's rate of $20.8 \%$ was much higher than the $9.6 \%$ reported in a 2013 study in nulliparas [5]. Again, suturing such slightly damaged perineum can be discussed in the interest of optimizing the perineal comfort of patients. Several studies show that not suturing the skin reduces perineal pain and dyspareunia, without increasing the risk of the wound's reopening [23]. No third- or fourth-degree

Table 2 Impact of Couder's maneuver on perineal lesion types

\begin{tabular}{llll}
\hline & Couder group $(n=101)$ & Control group $(n=98)$ & $p$-value \\
\hline Posterior perineum: & & & $14(14.3 \%)$ \\
- Intact perineum & $21(20.8 \%)$ & $55(56.1 \%)$ & NS \\
- First degree & $71(70.3 \%)$ & $29(29.6 \%)$ & 0.03 \\
- Second degree & $9(8.9 \%)$ & $36(36.7 \%)$ & $32(88.9 \%)$ \\
Anterior perineum: & $44(43.6 \%)$ & $4(11.1 \%)$ \\
- Labial tears & $38(86.4 \%)$ & NS \\
- periurethral tears & $6(13.6 \%)$ & & \\
\hline
\end{tabular}


perineal tears were observed during this study, which is in line with the very low rate in our department - respectively, $4 \%$ and $2 \%$ based on our 2010 study [24]. There was no significant difference in the rate of anterior perineal lesions in the two groups $(p=0.33)$.

This maneuver does not aim to overmedicalize childbirth. It should be assimilated as a continuation of the maneuver of lowering the fetal head and aiding the natural movement of restitution. Indeed, in the lithotomy birthing position, and unlike the lateral or upright positions, in which the posterior shoulder is delivered first, it is the manual assistance of the movement of restitution, which, by tensing the sternocleidomastoid muscle, leads to the delivery of the anterior shoulder, first. $\mathrm{CM}$ is simply the logical continuation of managing this anterior upper limb by completely lowering it under the pubic symphysis. Lowering the anterior arm in a calm and controlled fashion does not in any way delay fetal expulsion. The fetal head must be delivered carefully to manage the perineum as to avoid severe perineal trauma, but carefully managing delivery of the shoulders also contributes to reducing lesions.

The failure rate was estimated at 3\%. Even though no cases of obstetric fracture were reported in our series, this risk does exist, in particular for the humerus, and it results from poor execution and pulling perpendicularly to the axis of the arm. The prognostic for these fractures is, however, very good. Immobilization is most often all that is required, and remodeling is complete after 6 months $[25,26]$.

\section{Strengths and limitations}

This study provides an objective view of our clinical practice. The design is simple with a significant statistical power demonstrating the feasibility and benefit of this maneuver. In a previous study, we reported that our policy of restricting the use of episiotomy did not increase the risk of third- and fourth-degree perineal tears, with a rate of episiotomy of barely more than $1 \%$ [6]. This policy of highly selective use led to a statistically significant increase in the rate of intact perineums, allowing more than $85 \%$ of patients who gave birth vaginally to leave our maternity department with trauma that was less severe than that associated with episiotomy. Thus, results of this present study are not applicable in all maternity wards where episiotomy is regularly performed.

Futhermore, the use of CM must be taught and supervised in a non-trained team. Indeed, operators who use it to early, based on a misunderstanding or anxiety can interfere with normal restitution and interfere with normal shoulder delivery. Training sessions are necessary to safely practice this technique in delivery rooms. In our study, professionals who took part to the study were volunteer and accustomed to practice this maneuver at delivery. External validity could be lost when $\mathrm{CM}$ is performed without prior teaching.

Others limitations of the study are absence of blinding and randomization. Lack of blinding can lead to the operator classifying tears as not in need of suturing. They may classify small second-degree tears as first degree. In our teaching maternity, three professionals are present with the parturient in the delivery room: a midwife, a student midwife and a child care assistant. It was difficult for ethics reasons to propose a perineal examination by a fourth blinded person while preserving women's intimacy after delivery. Intimacy has to be ensured according to the French hospitalized patient Charter [27]. Perineal tears could have been photographed before and after $\mathrm{CM}$, but the interpretation would have been difficult and not contributive. No randomization was performed for this study because it was a prospective collection of data following the introduction of a new maneuver in current practice. It was necessary to ensure the feasibility of the maneuver by midwives before considering a randomised trial.

\section{Comparison with published data}

Different means of prevention have been reported in the literature. According to the Cochrane database, involving four studies with a total of 2480 patients, performing a prenatal perineal massage reduced the incidence of perineal tears requiring suturing, with $\mathrm{RR}=0.91 \quad$ (CI 95\%: 0.86-0.96) [28]. This difference was only significant in patients who had never delivered vaginally. However, no difference in the incidence of first- and second-degree perineal tears was found. Ruckhaberle et al. have reported a significant increase in the rate of intact perineums $(37.4 \%$ vs. 25.7\%; $p=0.05)$ in patients using an intravaginal balloon called EPI-NO ${ }^{\circ}$ from 37 weeks of gestation onward [29]. Using it daily progressively dilates the vagina, the aim being to ensure better perineal stretch during delivery. However, there was no significant difference in the reduction of first- and second-degree perineal trauma $(p=0.81)$ rates in that study. The results on the use of hyaluronic acid are contradictory. According to Scarabatto et al., in a randomized prospective study in 139 nulliparae, there was a significant reduction in perineal trauma $(39.4 \%$ vs. $76.5 \%)$ when this product was used [30]. Conversely, Colacioppo et al. found that its use did not reduce the rate of perineal tears and did not increase the number of intact perineums in a randomized prospective study [31]. Given our results, CM could be performed in nulliparae who do not undergo episiotomy for delivery of the fetal head in order to reduce the rate of second-degree perineal tears. 
The extent of muscle tear is correlated with the extent to which the muscle fibers are stretched [32-34]. In CM, the posterior shoulder exerts less pressure on these muscles, which is therefore a further advantage. The degree of morbidity is directly linked to the degree of perineal damage, and damage to the puborectal fascicles influences urinary and anorectal function [13]. For Rogers et al., patients who suffer perineal muscular trauma during childbirth require more perineal rehabilitation sessions (OR = 3.06; CI 95\%: 1.41-6.63) [35]. The integrity of the muscles and ligaments that make up the pelvic floor is crucial for ensuring sufficient pelvic floor equilibrium after childbirth [36]. It is recognized that any trauma of the levator ani muscle increases the risk of pelvic organ prolapse [37]. Muscle tear is often accompanied by nerve trauma that may worsen both disorders of the pelvic floor and urinary sphincter functions [38, 39]. According to a case-control study in 68 patients with anal incontinence, Bharucha et al. revealed that puborectal muscle trauma was significantly associated with a deterioration of voluntary sphincter contractility $(p=0.05)$ [40]. All these dysfunctions significantly lower patient's quality of life [41]. These results show why it is essential to avoid second-degree perineal trauma during childbirth, especially in nulliparae, who are recognized as being at risk of perineal trauma [42].

\section{Conclusion}

This is the first study reporting a means of significantly reducing the incidence of second-degree perineal lesions without recourse to episiotomy, and it is the first series describing the use of $\mathrm{CM}$ in nulliparous patients. The maneuver improves the overall rate of perineal tears, reducing second-degree perineal tears in a highly significant manner $(p<0.01)$ without increasing trauma to the urogenital triangle. It thus lowers the number of sutures required. This study may provide a rationale for systematically using CM in nulliparous patients when an episiotomy has not been performed. These results encourage continuing and improving this work with a future randomized study.

\section{Additional file}

Additional file 1: Descriptive statisitics of the study. (XLS $76 \mathrm{~kb})$

\section{Abbreviations}

CM: Couder's Maneuver; BMI: Body mass index

\section{Acknowledgements}

We thanks all the midwives and obstetricians who informed and included the patients, the women who accepted to take parts in this research and Gabrielle Cremer who provided medical writing services.
Funding

The study was not funded.

\section{Availability of data and materials}

The data that support the findings of this study are available on request from the corresponding author [NM]. The data are not publicly available due to them containing information that could compromise research participant privacy.

\section{Authors' contributions}

NM designed the study, collected data and wrote the manuscript. MB designed the study, performed the analysis and wrote the manuscript. AEL, RR and DR collected data and helped to draft manuscript. All authors read and approved final version of the manuscript.

\section{Competing interests}

The authors declare that they have no competing interests.

\section{Consent for publication}

Not applicable.

\section{Ethics approval and consent to participate}

Anonymity of patient identifiable information was maintained and written consent for participation was obtained from participant. The study was a clinical practice evaluation and respected ethical rules set by our local ethical committee (Comité Protection des Personnes CPP EST II). Registered number was not requested.

\section{Publisher's Note}

Springer Nature remains neutral with regard to jurisdictional claims in published maps and institutional affiliations.

Received: 14 January 2016 Accepted: 5 May 2017

Published online: 12 May 2017

References

1. Valsky DV, Lipschuetz M, Bord A, Eldar I, Messing B, Hochner-Celnikier D, et al. Fetal head circumference and length of second stage of labor are risk factors for levator ani muscle injury, diagnosed by 3-dimensional transperineal ultrasound in primiparous women. Am J Obstet Gynecol. 2009;201(1):91. e1-7.

2. Nyangoh Timoh K, Bessede T, Zaitouna M, Peschaud F, Chevallier J-M, Fauconnier A, et al. Anatomy of the levator ani muscle and implications for obstetrics and gynaecology. Gynécologie Obstétrique Fertil janv. 2015;43(1): 84-90.

3. Shek KL, Dietz HP. Intrapartum risk factors for levator trauma. BJOG Int J Obstet Gynaecol nov. 2010;117(12):1485-92.

4. Henderson J, Burns EE, Regalia AL, Casarico G, Boulton MG, Smith LA. Labouring women who used a birthing pool in obstetric units in Italy: prospective observational study. BMC Pregnancy Childbirth. 2014;14:17.

5. Smith LA, Price N, Simonite $V$, Burns EE. Incidence of and risk factors for perineal trauma: a prospective observational study. BMC Pregnancy Childbirth. 2013;13:59.

6. Schwertner-Tiepelmann N, Thakar R, Sultan AH, Tunn R. Obstetric levator ani muscle injuries: current status. Ultrasound Obstet Gynecol Off J Int Soc Ultrasound Obstet Gynecol. 2012;39(4):372-83.

7. Jönsson ER, Elfaghi I, Rydhström H, Herbst A. Modified Ritgen's maneuver for anal sphincter injury at delivery: a randomized controlled trial. Obstet Gynecol. 2008;112(2):212-7.

8. Cunningham JD. Experiences of Australian mothers who gave birth either at home, at a birth centre, or in hospital labour wards. Soc Sci Med 1982. 1993;36(4):475-83.

9. Pirhonen JP, Grenman SE, Haadem K, Gudmundsson S, Lindqvist P, Siihola S, et al. Frequency of anal sphincter rupture at delivery in Sweden and Finland-result of difference in manual help to the baby's head. Acta Obstet Gynecol Scand. 1998;77(10):974-7.

10. Hals E, Oian P, Pirhonen T, Gissler M, Hjelle S, Nilsen EB, et al. A multicenter interventional program to reduce the incidence of anal sphincter tears. Obstet Gynecol. 2010;116(4):901-8.

11. Jansova M, Kalis V, Rusavy Z, Zemcik R, Lobovsky L, Laine K. Modeling manual perineal protection during vaginal delivery. Int Urogynecology J. 2014;25(1):65-71. 
12. Stedenfeldt M, Øian P, Gissler M, Blix E, Pirhonen J. Risk factors for obstetric anal sphincter injury after a successful multicentre interventional programme. BJOG Int J Obstet Gynaecol. 2014;121(1):83-91.

13. Aasheim V, Nilsen ABV, Lukasse M, Reinar LM. Perineal techniques during the second stage of labour for reducing perineal trauma. Cochrane Database Syst Rev. 2011;7(12):CD006672.

14. French College of Obstetricians and Gynecologists. Recommandations pour la pratique clinique. Dystocie des épaules. Available at http://www.cngof.fr/ pratiques-cliniques/. 2016.

15. Winn HN, Hobbins JC. Clinical Maternal-Fetal Medicine. Chapter: The mechanism of shoulder dystocia: CRC Press; 2000. p. 185-186.

16. Royal College of Obstetricians and Gynecologists. National Institute for Health and Clinical Excellence. Intrapartum Care: Care of Healthy Women and Their Babies During Childbirth. London,RCOG; 2007. Available at: www. nice.org.uk/nicemedia/pdf/IPCNICEGuidance.pdf. Accessed 9 June 2009.

17. Temerinac $D$, Chen $X$, Sütterlin M, Kehl S. Influence of fetal birth weight on perinatal outcome in planned vaginal births. Arch Gynecol Obstet. 2014; 289(2):313-8.

18. Chehab M, Courjon M, Eckman-Lacroix A, Ramanah R, Maillet R, Riethmuller D. Impact of a major decrease in the use of episiotomy on perineal tears in a level III maternity ward. J Gynécologie Obstétrique Biol Reprod. 2014:43(6):463-9.

19. Bick DE, Kettle C, Macdonald S, Thomas PW, Hills RK, Ismail KMK. Perineal Assessment and Repair Longitudinal Study (PEARLS): protocol for a matched pair cluster trial. BMC Pregnancy Childbirth. 2010;10:10.

20. Bick DE, Ismail KM, Macdonald S, Thomas P, Tohill S, Kettle C. How good are we at implementing evidence to support the management of birth related perineal trauma? A UK wide survey of midwifery practice BMC Pregnancy Childbirth. 2012:12:57.

21. Dietz HP, Simpson JM. Levator trauma is associated with pelvic organ prolapse. BJOG Int J Obstet Gynaecol. 2008;115(8):979-84.

22. Heilbrun ME, Nygaard IE, Lockhart ME, Richter HE, Brown MB, Kenton KS, et al. Correlation between levator ani muscle injuries on magnetic resonance imaging and fecal incontinence, pelvic organ prolapse, and urinary incontinence in primiparous women. Am J Obstet Gynecol. 2010;202(5):488. e1-6.

23. Oboro VO, Tabowei TO, Loto OM, Bosah JO. A multicentre evaluation of the twolayered repair of postpartum perineal trauma. J Obstet Gynaecol. 2003;23(1):5-8.

24. Eckman A, Mottet N, Ramanah R, Riethmuller D. Delivery of premature infants. J Gynécologie Obstétrique Biol Reprod. 2015;44(8):781-6.

25. Sherr-Lurie N, Bialik GM, Ganel A, Schindler A, Givon U. Fractures of the humerus in the neonatal period. Isr Med Assoc J. 2011;13(6):363-5.

26. Husain SN, King EC, Young JL, Sarwark JF. Remodeling of birth fractures of the humeral diaphysis. J Pediatr Orthop. 2008;28(1):10-3.

27. Ministère des Affaires sociales, de la Santé et des Droits des femmes. Available at: http://social-sante.gouv.fr/IMG/pdf/charte_a4_couleur.pdf.

28. Beckmann MM, Garrett AJ. Antenatal perineal massage for reducing perineal trauma. Cochrane Database Syst Rev. 2013;4:CD005123.

29. Ruckhäberle E, Jundt K, Bäuerle M, Brisch K-H, Ulm K, Dannecker C, et al. Prospective randomised multicentre trial with the birth trainer EPI-NO for the prevention of perineal trauma. Aust N Z J Obstet Gynaecol. 2009;49(5):478-83.

30. Scarabotto LB, Riesco MLG. Use of hyaluronidase to prevent perineal trauma during spontaneous delivery: a pilot study. J Midwifery Womens Health. 2008;53(4):353-61.

31. Colacioppo PM, Gonzalez Riesco ML, Koiffman MD. Use of hyaluronidase to prevent perineal trauma during spontaneous births: a randomized, placebocontrolled, double-blind, clinical trial. J Midwifery Womens Health. 2011; 56(5):436-45.

32. Brooks SV, Zerba E, Faulkner JA. Injury to muscle fibres after single stretches of passive and maximally stimulated muscles in mice. J Physiol. 1995:488(Pt 2):459-69.

33. Lien K-C, Mooney B, DeLancey JOL, Ashton-Miller JA. Levator ani muscle stretch induced by simulated vaginal birth. Obstet Gynecol. 2004;103(1):31-40.

34. Hoyte L, Damaser MS, Warfield SK, Chukkapalli G, Majumdar A, Choi DJ, et al. Quantity and distribution of levator ani stretch during simulated vaginal childbirth. Am J Obstet Gynecol. 2008;199(2):198. e1-5.

35. Rogers RG, Leeman LM, Migliaccio L, Albers LL. Does the severity of spontaneous genital tract trauma affect postpartum pelvic floor function? Int Urogynecol J Pelvic Floor Dysfunct. 2008;19(3):429-35.

36. Bortolini M a T, Drutz HP, Lovatsis D, Alarab M. Vaginal delivery and pelvic floor dysfunction: current evidence and implications for future research. Int Urogynecology J. 2010;21(8):1025-30.
37. Handa VL, Blomquist JL, Knoepp LR, Hoskey KA, McDermott KC, Muñoz A. Pelvic floor disorders 5-10 years after vaginal or cesarean childbirth. Obstet Gynecol. 2011;118(4):777-84.

38. Baessler K, Schuessler B. Childbirth-induced trauma to the urethral continence mechanism: review and recommendations. Urology. 2003;62(4):39-44.

39. Eason $\mathrm{E}$, Labrecque $\mathrm{M}$, Wells $\mathrm{G}$, Feldman P. Preventing perineal trauma during childbirth: a systematic review. Obstet Gynecol. 2000;95(3):464-71.

40. Bharucha AE, Fletcher JG, Melton LJ, Zinsmeister AR. Obstetric trauma, pelvic floor injury and fecal incontinence: a population-based case-control study. Am J Gastroenterol. 2012;107(6):902-11.

41. Pollack J, Nordenstam J, Brismar S, Lopez A, Altman D, Zetterstrom J. Anal incontinence after vaginal delivery: a five-year prospective cohort study. Obstet Gynecol. 2004;104(6):1397-402.

42. Albers L, Garcia J, Renfrew M, McCandlish R, Elbourne D. Distribution of genital tract trauma in childbirth and related postnatal pain. Birth Berkeley Calif. 1999;26(1):11-7.

\section{Submit your next manuscript to BioMed Central and we will help you at every step:}

- We accept pre-submission inquiries

- Our selector tool helps you to find the most relevant journal

- We provide round the clock customer support

- Convenient online submission

- Thorough peer review

- Inclusion in PubMed and all major indexing services

- Maximum visibility for your research

Submit your manuscript at www.biomedcentral.com/submit
) Biomed Central 